\author{
開空間における放射クラスタ制御* \\ (放射クラスタ制御系の理論的構築) \\ 貝塚 勉*1, 田中信 雄 ${ }^{* 2}$

\section{Radiation Cluster Control in a Free Field \\ (Theoretical Development of Radiation Cluster Control System)} \\ Tsutomu KAIZUKA and Nobuo TANAKA*3 \\ ${ }^{* 3}$ Department of Aerospace Engineering, Tokyo Metropolitan University, \\ 6-6 Asahigaoka, Hino-shi, Tokyo, 191-0065 Japan

\begin{abstract}
Radiation cluster control is proposed for the purpose of attenuating harmonic sound radiation into a free field using error signals derived from structural vibration sensors. The approach falls into a category of MAC (middle authority control) between used LAC (low authority control : structural modal control) and HAC (high authority control: radiation modal control), possessing the benefit of practicality of LAC, while providing high control performance as well as flexibility of control gain assignment similar to HAC. The structure of radiation cluster control system is outlined, showing that it is possible to control a target cluster without affecting the other clusters. A design procedure for the radiation cluster control system is proposed.
\end{abstract}

Key Words: Sound and Acoustic, Sound Field Control, Noise Control, Sound Radiation

\section{1. 緒言}

本論文は, 構造物から開空間へ放射される騒音 (以 下, 放射音と呼ぶ)のアクティブ制御に関連するもの である.一般に, 放射音の大局的静肃化を志向する場 合, 評価関数として音響パワー[1][2]を採用することが 理想とされている. 音響パワーは, マイクロホン・ア レイを用いた音響計測によって取得できるが,このよ うな計測システムは,省スペースや省コストの観点か ら現実的ではない. 結局, 音響計測を基調とする制御 系は, 放射音の局所的静肃化に適合した技術であり， 大局的静肃化には不適合な技術といえる.

以上の経緯から, 音響工学者達の関心は, 構造計測 を基調とする音響パワー制御一遷移していった.これ は, 騒音源である構造物の振動計測を基にして, 放射 される音響パワーを予測するという試みである.ここ で留意すべきは,構造場に対する直交因子である構造 モードが, 音響場においては直交因子であり得ないこ とである ${ }^{[3]}$. 換言すれば, 構造モードは, 音響場にお いて互いに連成するということである.このことは， 構造モードの抑制が, 音響パワーの抑制に必ずしも結 びつかないことを意味している ドの計測／制御に基礎を置く従来の振動制御理論で は，合理的な放射音制御を成就できない.

\footnotetext{
* 原稿受付 2006 年 4 月 14 日.

*1 准員, 首都大学東京大学院システムデザイン研究科 (丞 191 0065 日野市旭が丘 6-6) [日本学術振興会特別研究員 DCI].

*2 正員, フェロー, 首都大学東京システムデザイン学部.

E-mail: ntanaka@cc.tmit.ac.jp
}

1990 年, Borgiotti ${ }^{161}$ は, 開空間における放射音問題 を対象として,構造場から音響場への直交因子を定式 化した.この直交因子は，一般に放射モード(radiation mode) と呼ばれる. 以降, 放射モ一ドの基本特性の解

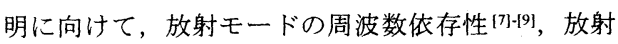
モード解析の精度検証 ${ }^{[9] 110]}$, 放射効率を規範とした放 射モードのグループ化 ${ }^{[11]}$ など, 精力的な研究が行わ れている.また, 放射モードの計測／制御に関する研

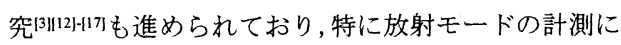
関する議論が大きな焦点となっている.放射モードの 計測には, 次の二つの方法がある. 一つは, センサ網 によって構造物全表面の振動速度を計測し, 当該計測 信号から放射モードを算出する方法 ${ }^{[13]}$. 一つは, 構造 モード・フィルタによって構造モード振幅を計測し， 当該計測信号から放射モードを算出する方法である [3].これら二つの方法は，互いに長所短所を有してい るものの, 結論を言えば, どちらも実用的とは言い難 い. 何故なら,これら計測システムの構築には, 構造 モード関数の既知, 放射抵抗の既知, 多数の集中定数 系センサの使用など, 厳しい前提を伴うからである.

本論文の目的は, 構造計測を採用する立場から, 実 用的かつ合理的な放射音制御系を提案することであ る. 本論文では, 幾何学形状, 材料の均質性, 境界条 件において対称性を満足する構造物（以下，対称構造 物と呼ぶ) を対象として, 放射モードとは異なる直交 因子を新たに定式化する，まず，定性的な理論とし て, 対称構造物の構造モード関数は, 偶関数か奇関数 
のいずれかに帰属する. そこで, 偶関数に帰属する全 ての構造モ一ドを一つの群れとして定義し, 同様に, 奇関数に帰属する全ての構造モードを一つの群れとし て定義する. 本論文では, このような構造モードの群 れをクラスタ (cluster) と呼称する. 次いで, クラスタ が音響場において互いに連成しないこと，すなわち， クラスタが音響場に対する直交因子であることを数学 的に証明する. 本論文では, 当該クラスタのことを放 射クラスタ (radiation cluster) と呼称する.ここで, 放 射モードと放射クラスタの違いは, 前者がモード単位 の直交因子であるのに対し, 後者がクラスタ単位の直 交因子であることに帰着する.つまり, 直交因子とし ての精緻性といら観点からすれば, 放射クラスタは, 放射モードの下位概念に相当する.さらに, 本論文で は,放射クラスタの計測／制御システムを理論的に構 筑する. 放射クラスタの計測にあたっては, 構造モー ド関数, 放射抵抗, 多数の集中定数系センサを必要と しない. 結局, 放射クラスタ制御とは, タラスタ単位 の直交因子を設計思想の中核に置く合理性と, 比較的 簡素な構成で制御系を運用できる実用性とを兼備した 放射音制御系である.ところで, 放射クラスタ制御に 関連する研究は, 開空間における周辺単純支持矩形平 板の放射音問題[18][19], 対称構造を有する閉空間におけ る放射音問題 ${ }^{[20]}$ を対象として既に報告されている. したがって, 本論文は, 文献[18]-[20]の姉妹論文とし ての側面を持つ.

\section{2. 在来の放射音制御 : LAC と HAC}

第2章では, 構造計測を基調とする放射音制御に関 連する過去の研究を整理し, 各種制御法の合理性と実 用性を総括する. その意図は, 第3 章にて提案する放 射クラスタ制御と在来の放射音制御との体系化にあ る. 第1節では, 開空間における音響パワーを次の二 通りに定式化する.一つは, 構造物表面における横振 動の複素速度を陽とした音響パワーの記述式. 一つ は, 構造モード振幅を陽とした音響パワーの記述式で ある.これらの定式化を通して, 複素速度および構造 モード振幅が, 音響パワーに対する直交因子でないこ とを示す. 第2節では, 第 1 節にて導出した複素速度 形式, 構造モード振幅形式の音響パワーを出発点とし て, 各形式に則った放射モードを導出する. また, 放 射モード制御の合理性について解説すると共に, 当該 制御系の実用上の問題点を指摘する.

2. 1 音響パワー まず, 構造物表面上の複素速 度を陽にして音響パワーを定式化する.構造物の表面
を $M$ 個の要素に分割して考えたとき, $m(=1,2, \cdots, M)$ 番要素の複素速度 $v\left(\mathbf{r}_{m}, \omega\right)$ は, 次式で与えられる ${ }^{[13]}$.

$v\left(\mathbf{r}_{m}, \omega\right)=\Psi^{T}\left(\mathbf{r}_{m}\right) \mathbf{a}(\omega)$

ただし, $\mathbf{r}_{m}$ を $m$ 番要素の中心座標, $\omega$ を角振動数, $\psi\left(\mathbf{r}_{m}\right) \in \mathbb{R}^{N \times 1}$ を構造モード質量に対し正規化された構 造モード関数ベクトル, $\mathbf{a}(\omega) \in \mathbb{C}^{N \times 1}$ を構造モード振幅 ベクトル, $N$ を考慮する構造モードの総数, ${ }^{r}$ を転置と する. なお, $\psi\left(\mathbf{r}_{m}\right)$ および $\mathbf{a} は$, 極めて単純な構造物 を除いて解析的に得ることが困難だが, 実験モード解 析やFEMを用いることで近似的／数值的に得ること が可能である[21. さて, 各要素の複素速度をベクトル 形式で整理すると, 次式のようになる.

$\mathbf{v}(\omega)=\left[\begin{array}{lll}v\left(\mathbf{r}_{1}, \omega\right) & \cdots & v\left(\mathbf{r}_{M}, \omega\right)\end{array}\right]^{T}=\Psi^{T} \mathbf{a}(\omega) \in \mathbb{C}^{M \times 1}$

ただし，

$\Psi=\left[\begin{array}{lll}\Psi\left(\mathbf{r}_{1}\right) & \cdots & \psi\left(\mathbf{r}_{M}\right)\end{array}\right] \in \mathbb{R}^{N \times M}$

ここで, 全要素の表面上の複素音圧 $\mathbf{p}(\omega) \in \mathbb{C}^{M \times 1}$ を考 える. このとき, $\mathbf{p}(\omega)$ と $\mathbf{v}(\omega)$ の間には, 次式の関係 が成立する ${ }^{[13]}$.

$\mathbf{p}(\omega)=\left[\begin{array}{lll}p\left(\mathbf{r}_{1}\right) & \cdots & p\left(\mathbf{r}_{M}\right)\end{array}\right]^{T}=\mathbf{Z}(\omega) \mathbf{v}(\omega)$

なお, 音響インピーダンス・マトリクス $\mathbf{Z}(\omega) \in \mathbb{C}^{M \times M}$ は, 正定な対称マトリクスでありツ, 構造物の幾何学 形状および周波数に依存する. $\mathbf{Z}(\omega)$ は, 極めて限ら れた場合を除いて解析解を得ることが難しく, レイ リ一積分やBEMを用いて近似的／数値的な解を得る ことになる ${ }^{100}$. そして, 式(2),(4)を次式に示す音響パ ワー $W(\omega)$ の定義式 $|5| に$ 代入することで, $M$ 個の要素 から放射される音響パワーを求められる。

$W(\omega)=\frac{S}{2} \operatorname{Re}\left[\mathbf{v}^{H}(\omega) \mathbf{p}(\omega)\right]$

ただし, $S$ を要素毎の表面積（簡単のため, 各要素の 表面積を等しいと仮定する.) ${ }^{H}$ を複素共役転置とす る. 式(4)を式(5)へ代入することで, 音響パワーを複 素速度の二次形式で記述できる.

$W(\omega)=\frac{S}{2} \operatorname{Re}\left[\mathbf{v}^{H}(\omega) \mathbf{Z}(\omega) \mathbf{v}(\omega)\right]$

$=\frac{S}{4} \mathbf{v}^{H}(\omega) \operatorname{Re}\left[\mathbf{Z}(\omega)+\mathbf{Z}^{H}(\omega)\right] \mathbf{v}(\omega)=\mathbf{v}^{H}(\omega) \mathbf{R}(\omega) \mathbf{v}(\omega)$ ただし，

$\mathbf{R}(\omega)=\frac{S}{2} \operatorname{Re}[\mathbf{Z}(\omega)] \in \mathbb{R}^{M \times M}$

式(7)から明らかなように, 放射抵抗マトリクス $\mathbf{R}(\omega)$ 
は，正定な実対称マトリクスである.また， $\mathbf{R}(\omega)$ は， 一般に対角マトリクスでないことに留意されたい.す ると, 式(6)から, 複素速度 $\mathbf{v}(\omega)$ は, 音響パワーに対 する直交因子でないことが理解できる.すなわち, 構 造物表面における複素速度を抑制したところで, 音響 パワーが抑制される保証は無い‘3\}.

続いて,構造モード振幅を陽にして音響パワーを定 式化する．そのために，式(2)を式(6)に代入する.

$W(\omega)=\mathbf{a}^{H}(\omega) \mathbf{M}(\omega) \mathbf{a}(\omega)$

ただし，

$\mathbf{M}(\omega)=\boldsymbol{\Psi} \mathbf{R}(\omega) \Psi^{T} \in \mathbb{R}^{N \times N}$

ここで, 放射抵抗マトリクス $\mathbf{M}(\omega)$ は, 正定な実対称 マトリクスである.また, $\mathbf{M}(\omega)$ は，一般に対角マト リクスでないことに留意されたい, すると, 式(8)か ら, 構造モード振幅 $\mathbf{a}(\omega)$ は, 音響パワーに対する直 交因子でないことが理解できる.すなわち, 構造モ一 ド振幅を抑制したところで, 音響パワーが抑制される 保証は無い[3].

以上のとおり, 複素速度や構造モード振幅の計測／ 制御に基礎を置く従来の振動制御理論では，音響パ ワーを合理的に抑制できない. 本論文では, 放射音制 御系としての合理性に乏しいという意味で, 複素速度 あるいは構造モード振幅の計測／制御に基礎を置く制 御理論を LAC(low authority control) と位置付ける.

2.2 放射モード＼cjkstart本節では, 音響パワーに対す る直交因子として放射モードを定式化する.なお, 放 射モードは, 前節にて示した二通りの音響パワー記述 式に準ずるかたちで，二通りに導出できる，一つは， 式(6)の複素速度形式からの導出.一つは, 式(8)の構 造モード振幅形式からの導出である. 後述のように, いずれの立場を取るかによって, 放射モード計測シス テムの設計戦略に大きな違いが生じることになる.

まず，複素速度形式からの放射モード導出を考え る. 式(6)は, 複素速度 $\mathbf{v}(\omega)$ が音響パワーに対する直 交因子でないことを示唆していると述べたが，これ は, $\mathbf{R}(\omega)$ が非対角マトリクスであることに起因する. ここで, $\mathbf{R}(\omega)$ を対角化できたならば，直交因子を見 出せるはずである，幸いにも，式(7) で定義される $\mathbf{R}(\omega)$ は, 正定な実対称マトリクスであるため, 次式 のように対角化できる ${ }^{[3][13] . ~}$

$\mathbf{R}(\omega)=\mathbf{Q}^{T}(\omega) \Lambda(\omega) \mathbf{Q}(\omega) \in \mathbb{R}^{M \times M}$

ただし, $\mathbf{Q}(\omega) \in \mathbb{R}^{M \times M}$ を $\mathbf{R}(\omega)$ の固有べクトルから成
る直交マトリクス, $\Lambda(\omega) \in \mathbb{R}^{M \times M}$ を $\mathbf{R}(\omega)$ の固有值を 要素に持つ対角マトリクスとする. 式(10)を式(6)へ 代入すると, 次式を得る.

$W(\omega)=\mathbf{y}^{H}(\omega) \Lambda(\omega) \mathbf{y}(\omega)$

ただし，

$\mathbf{y}(\omega)=\mathbf{Q}(\omega) \mathbf{v}(\omega) \in \mathbb{C}^{M \times 1}$

式 (12) で定義される $\mathrm{y}(\omega)$ は, 複素速度形式の放射 モード振幅ベクトルに該当する.また, $\mathbf{Q}(\omega)$ を構成 する固有べクトルは, 放射モード形状に該当し, $\Lambda(\omega)$ の対角要素は, 放射効率に比例する值に該当す る.式(11)から明らかなように, 放射モードは, 音響 パワーに対する直交因子に他ならない, すなわち, 放 射モード振幅 $\mathbf{y}(\omega)$ の抑制は, 音響パワーの抑制を保 証する ${ }^{[3] \mid 13] . ~}$

ここで, 複素速度形式の放射モード $\mathbf{y}(\omega)$ の計測方 法について考察する. 式(12)から明らかなように, 放 射モード振幅 $\mathbf{y}(\omega)$ は, 複素速度 $\mathbf{v}(\omega)$ を取得した後, さらに $\mathbf{v}(\omega)$ をフィルタ $\mathbf{Q}(\omega)$ に通すことで計測でき る. 複素速度 $\mathbf{v}(\omega)$ を取得するには, 構造物表面を覆 うように集中定数系センサを離散的に配置し, 各点の 速度情報を同時に計測する必要がある.また, フィル タ $\mathbf{Q}(\omega)$ を設計するには, 放射抵抗マトリクス $\mathbf{R}(\omega)$ の既知を前提とする.これに加えて,フィルタ $\mathbf{Q}(\omega)$ の周波数依存性が, 当該計測システムを一層複雑なも のにしている.（ただし，フィルタ $\mathbf{Q}(\omega)$ の周波数依

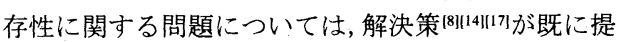
案されている.)

続いて,構造モード振幅形式からの放射モード導出 を考える. 式 $(8)$ は, 構造モード振幅 $\mathbf{a}(\omega)$ が音響パ ワーに対する直交因子でないことを示唆していると述 ベたが，これは， $\mathbf{M}(\omega)$ が非対角マトリクスであるこ とに起因する.ここで, $\mathbf{M}(\omega)$ を対角化できたならば, 直交因子を見出せるはずである，幸いにも，式(9)で 定義される $\mathbf{M}(\omega)$ は, 正定な実対称マトリクスである ため, 次式のように対角化できる ${ }^{[3 ! 13]}$.

$\mathbf{M}(\omega)=\mathbf{P}^{T}(\omega) \boldsymbol{\Omega}(\omega) \mathbf{P}(\omega) \in \mathbb{R}^{N \times N}$

ただし, $\mathbf{P}(\omega) \in \mathbb{R}^{N \times N}$ を $\mathbf{M}(\omega)$ の固有ベクトルから成 る直交マトリクス, $\boldsymbol{\Omega}(\omega) \in \mathbb{R}^{N \times N}$ を $\mathbf{M}(\omega)$ の固有値を 対角要素に持つ対角マトリクスとする.式(13)を式(8) 一代入すると, 次式を得る.

$W(\omega)=\mathbf{b}^{H}(\omega) \boldsymbol{\Omega}(\omega) \mathbf{b}(\omega)$

ただし， 
$\mathbf{b}(\omega)=\mathbf{P}(\omega) \mathbf{a}(\omega) \in \mathbb{C}^{N \times 1}$

式(15)で定義される $\mathbf{b}(\omega)$ は, 構造モード振幅形式の 放射モード振幅べクトルに該当する。また， $\mathbf{P}(\omega) \in \mathbb{R}^{N \times M}$ を構成する固有ベクトルは, 放射モ一 ド形状に該当し， $\Omega(\omega)$ の対角成分は, 放射効率に比 例する值に該当する. 式(14)が示すように, 放射モ一 ドは, 音響パワーに対する直交因子に他ならない.す なわち, 放射モード振幅 $\mathbf{b}(\omega)$ の抑制は, 音響パワー の抑制を保証する.

ここで, 構造モード振幅形式の放射モード振幅 $\mathbf{b}(\omega)$ の計測方法について考察する. 式(15)から明ら かなように, 放射モード振幅 $\mathbf{b}(\omega)$ は, 構造モード振 幅 $\mathbf{a}(\omega)$ を取得した後, さらに $\mathbf{a}(\omega)$ をフィルタ $\mathbf{P}(\omega)$ に通すことで計測できる. 構造モード振幅 $\mathbf{a}(\omega)$ を取 得するには, 構造モード・フィルタを構築する必要が ある. なお, 構造モード・フィルタの設計にあたって は, 構造モード関数の既知を前提とする. また, フィ ルタ $\mathbf{P}(\omega)$ を設計するには, 放射抵抗マトリクス $\mathbf{M}(\omega)$ の既知を前提とする. 加えて, フィルタ $\mathbf{P}(\omega)$ の周波数依存性が, 当該計測システムを一層複雑なも のにしている.(ただし,フィルタ $\mathbf{P}(\omega)$ の周波数依存

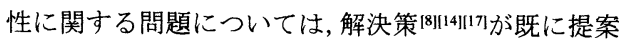
されている.）特筆すべきは, 構造モード・フィルタ を分布定数系センサにより構筑することで, 使用する センサの数を大幅に削減できることである ${ }^{[3]}$.つま り, 構造モード振幅形式の放射モード振幅 $\mathbf{b}(\omega)$ を計 測する場合には, 複素速度形式の放射モード $\mathbf{y}(\omega)$ を 計測するときのように膨大な数の集中定数系センサを 使用せずに済む. しかし, その反面, 構造モード・フィ ルタの設計には，構造モード関数の既知が前提とな る.したがって、いずれの形式の放射モードを計測す る場合にも, 非常な苦労を伴うことになる.

結局, 放射モードに基礎を置く制御理論は, 音響パ ワーを確実に抑制し得るという意味で HAC(high authority control) として位置付けられるものの, 計測シ ステムの複雑化が障壁となるため, 実用困難な代物と 言わざるを得ない.

\section{3. 放射クラスタ制御：MACの提案}

本章では, 対称構造物を対象として, LACの実用性 とHACの合理性を折哀した放射音制御系を提案する. 第1節では, 構造物の対称性を規範として, 構造モ一 ド関数を偶関数と奇関数にクラスタ化することから始 める. 次に, 各クラスタが, 音響場において直交関係 にあることを数学的に証明する. 本論文では, 当該ク
ラスタのことを放射クラスタと呼称する．第 2 節で は,放射クラスタの計測／制御に関する理論を構築す る. 提案する制御系は, 直交因子の計測／制御を基調 とする合理的な放射音制御系であるのと同時に, 構造 モード関数, 放射抵抗, 膨大な数のセンサを要さない 実用的な放射音制御系である.

3. 1 放射クラスタ 対称構造物を考える場合, 構造モード関数は, 偶関数か奇関数のいずれかに帰属 する.ここで, 対称構造物の例を図1に示す. 図中の 構造物は, $x$ 方向に関してのみ対称性を満足している. したがって,このときの構造モード関数は, $x$ 方向に 関して偶関数か奇関数に帰属する. 本章では, 簡単の ため, 図1に示すような $x$ 方向に関してのみ対称性を 満足する構造物を対象として論旨を展開してゆく.た だし, 以下に提案する理論は, $x y$ 方向, $x y z$ 方向に関 して対称性を満足する構造物を考える場合にも拡張で きることに留意されたい.

構造物が $x$ 方向に関して対称性を有することに着目 して, 領域 $x>0$ の要素 $\mathbf{r}_{1, k}(k=1,2, \cdots, M / 2)$, 領域 $x<0$ の要素 $\mathbf{r}_{2, k}(k=1,2, \cdots, M / 2)$ を定義する（図 1 参 照). 構造モード関数が $x$ 方向に関して偶関数か奇関 数に帰属することを踏まえると,構造モード関数べク トル $\psi\left(\mathbf{r}_{m}\right)$ は, 次式のようにクラスタ化される.

$\psi\left(\mathbf{r}_{m}\right)=\left[\begin{array}{l}\Psi_{e}\left(\mathbf{r}_{m}\right) \\ \boldsymbol{\Psi}_{o}\left(\mathbf{r}_{m}\right)\end{array}\right] \in \mathbb{R}^{\left(N_{e}+N_{o}\right) \times 1}=\mathbb{R}^{N \times 1}$

偶関数に帰属するクラスタ $\Psi_{e}\left(\mathbf{r}_{m}\right) \in \mathbb{R}^{N_{e} \times 1}$, 奇関数に 帰属するクラスタ $\Psi_{o}\left(\mathbf{r}_{m}\right) \in \mathbb{R}^{N_{o} \times 1}$ は, それぞれ次式を 満足する.

$\psi_{e}\left(\mathbf{r}_{1, k}\right)=\Psi_{e}\left(\mathbf{r}_{2, k}\right)$

$\psi_{o}\left(\mathbf{r}_{1, k}\right)=-\psi_{o}\left(\mathbf{r}_{2, k}\right)$

このとき，式(3)は，次式に書き換えられる.

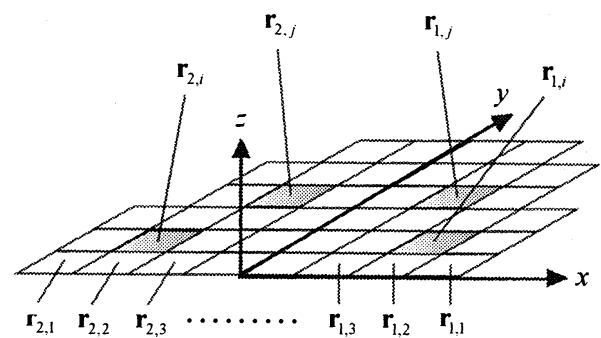

Fig. 1 An example of symmetric structures: Planar structure which has symmetry with respect to the $x$ direction. 
$\Psi=\left[\begin{array}{ll}\Psi_{e, 1} & \Psi_{e, 2} \\ \Psi_{o, 1} & \Psi_{o, 2}\end{array}\right]$

ただし，

$\Psi_{e, 1}=\left[\begin{array}{lll}\Psi_{e}\left(\mathbf{r}_{1,1}\right) & \cdots & \Psi_{e}\left(\mathbf{r}_{1, M / 2}\right)\end{array}\right] \in \mathbb{R}^{N_{e} \times M / 2}$

$\Psi_{e, 2}=\left[\begin{array}{lll}\Psi_{e}\left(\mathbf{r}_{2,1}\right) & \cdots & \Psi_{e}\left(\mathbf{r}_{2, M / 2}\right)\end{array}\right] \in \mathbb{R}^{N_{e} \times M / 2}$

$\Psi_{o, 1}=\left[\begin{array}{lll}\Psi_{o}\left(\mathbf{r}_{1,1}\right) & \cdots & \Psi_{o}\left(\mathbf{r}_{1, M / 2}\right)\end{array}\right] \in \mathbb{R}^{N_{e} \times M / 2}$

$\Psi_{o, 2}=\left[\begin{array}{lll}\Psi_{o}\left(\mathbf{r}_{2,1}\right) & \cdots & \Psi_{o}\left(\mathbf{r}_{2, M / 2}\right)\end{array}\right] \in \mathbb{R}^{N_{o} \times M / 2}$

このとき，次式が成り立つ。

$\Psi_{e, 1}=\Psi_{e, 2}$

$\Psi_{o, 1}=-\Psi_{o, 2}$

また, 式(7)は, 式(2),(4),(18)を考慮して, 次式に書 き換えられる。

$\mathbf{R}(\omega)=\left[\begin{array}{ll}\mathbf{R}_{1,1}(\omega) & \mathbf{R}_{1,2}(\omega) \\ \mathbf{R}_{2,1}(\omega) & \mathbf{R}_{2,2}(\omega)\end{array}\right]=\frac{S}{2} \operatorname{Re}\left[\left[\begin{array}{ll}\mathbf{Z}_{1,1}(\omega) & \mathbf{Z}_{1,2}(\omega) \\ \mathbf{Z}_{2,1}(\omega) & \mathbf{Z}_{2.2}(\omega)\end{array}\right]\right]$

このとき，次式が成り立つ。

$\mathbf{R}_{1,1}(\omega)=\mathbf{R}_{2,2}(\omega) \in \mathbb{R}^{M / 2 \times M / 2}$

$\mathbf{R}_{1,2}(\omega)=\mathbf{R}_{2,1}(\omega) \in \mathbb{R}^{M / 2 \times M / 2}$

また, 式(9)は, 次式に書き換えられる.

$\mathbf{M}(\omega)=\left[\begin{array}{ll}\mathbf{M}_{e, e}(\omega) & \mathbf{M}_{e, o}(\omega) \\ \mathbf{M}_{o, e}(\omega) & \mathbf{M}_{o, o}(\omega)\end{array}\right]$

ただし

$$
\begin{aligned}
& \mathbf{M}_{e, e}(\omega)=\left\{\Psi_{e, 1} \mathbf{R}_{1,1}(\omega)+\Psi_{e, 2} \mathbf{R}_{2,1}(\omega)\right\} \Psi_{e, 1}{ }^{T} \\
& +\left\{\Psi_{e, 1} \mathbf{R}_{1,2}(\omega)+\Psi_{e, 2} \mathbf{R}_{2,2}(\omega)\right\} \Psi_{e, 2}{ }^{T} \in \mathbb{R}^{N_{e} \times N_{e}} \\
& \mathbf{M}_{e, o}(\omega)=\left\{\Psi_{e, 1} \mathbf{R}_{1,1}(\omega)+\Psi_{e, 2} \mathbf{R}_{2,1}(\omega)\right\} \Psi_{o, 1}{ }^{T} \\
& +\left\{\Psi_{e, 1} \mathbf{R}_{1,2}(\omega)+\Psi_{e, 2} \mathbf{R}_{2,2}(\omega)\right\} \Psi_{o, 2}{ }^{T} \in \mathbb{R}^{N_{e} \times N_{o}} \\
& \mathbf{M}_{o, e}(\omega)=\left\{\Psi_{o, 1} \mathbf{R}_{1,1}(\omega)+\Psi_{o, 2} \mathbf{R}_{2,1}(\omega)\right\} \Psi_{e, 1}{ }^{T} \\
& +\left\{\Psi_{o, 1} \mathbf{R}_{1,2}(\omega)+\Psi_{o, 2} \mathbf{R}_{2,2}(\omega)\right\} \Psi_{e, 2}{ }^{T} \in \mathbb{R}^{N_{o} \times N_{e}} \\
& \mathbf{M}_{o, o}(\omega)=\left\{\Psi_{o, 1} \mathbf{R}_{1,1}(\omega)+\Psi_{o, 2} \mathbf{R}_{2,1}(\omega)\right\} \Psi_{o, 1}{ }^{T} \\
& +\left\{\Psi_{o, 1} \mathbf{R}_{1,2}(\omega)+\Psi_{o, 2} \mathbf{R}_{2,2}(\omega)\right\} \Psi_{o, 2}{ }^{T} \in \mathbb{R}^{N_{o} \times N_{o}}
\end{aligned}
$$

式(20),(22)を式(24)に代入すると, 次式を得る.

$$
\begin{aligned}
& \mathbf{M}_{e, e}(\omega)=2 \Psi_{e, 1}\left\{\mathbf{R}_{1,1}(\omega)+\mathbf{R}_{1,2}(\omega)\right\} \Psi_{e, 1}{ }^{T} \\
& \mathbf{M}_{e, o}(\omega)=\mathbf{0}
\end{aligned}
$$

$$
\begin{aligned}
& \mathbf{M}_{o, e}(\omega)=\mathbf{0} \\
& \mathbf{M}_{o, o}(\omega)=2 \Psi_{o, 1}\left\{\mathbf{R}_{1,1}(\omega)-\mathbf{R}_{1,2}(\omega)\right\} \Psi_{o, 1}{ }^{T}
\end{aligned}
$$

式(25)は, クラス夕間の直交性を明示している.すな わち, 当該クラスタは, 音響場に対する直交因子に他 ならない. 本論文では,これを放射クラスタ (radiation cluster) と命名する.

以上から, 式(8)に定義される音響パワーは, 次式 に展開できる.

$$
\begin{aligned}
& W(\omega)=\left[\begin{array}{l}
\mathbf{a}_{e}(\omega) \\
\mathbf{a}_{o}(\omega)
\end{array}\right]^{H}\left[\begin{array}{cc}
\mathbf{M}_{e, e}(\omega) & \mathbf{0} \\
\mathbf{0} & \mathbf{M}_{o, o}(\omega)
\end{array}\right]\left[\begin{array}{l}
\mathbf{a}_{e}(\omega) \\
\mathbf{a}_{o}(\omega)
\end{array}\right] \\
& =\mathbf{a}_{e}{ }^{H}(\omega) \mathbf{M}_{e, e}(\omega) \mathbf{a}_{e}(\omega)+\mathbf{a}_{o}{ }^{H}(\omega) \mathbf{M}_{o, o}(\omega) \mathbf{a}_{o}(\omega)(26)
\end{aligned}
$$

ただし, $\mathbf{a}_{e}(\omega) \in \mathbb{C}^{N_{e} \times 1}, \mathbf{a}_{o}(\omega) \in \mathbb{C}^{N_{o} \times 1}$ は, クラスタ化 された構造モード振幅ベクトルである.ささらに, 式 (26)は, 次式のように整理できる.

$W(\omega)=W_{e}(\omega)+W_{o}(\omega)$

ただし，

$W_{e}(\omega)=\mathbf{a}_{e}{ }^{H}(\omega) \mathbf{M}_{e, e}(\omega) \mathbf{a}_{e}(\omega)$

$W_{o}(\omega)=\mathbf{a}_{o}{ }^{H}(\omega) \mathbf{M}_{o, o}(\omega) \mathbf{a}_{o}(\omega)$

式(28)は, 音響パワーの放射クラスタ成分を表してい る.そして, 式(27)に示すように, 音響パワーは, 各 放射クラスタ成分の和として記述される.

以上では,『音響場（音響パワー）に対するクラス 夕単位の直交因子』として放射クラスタを定式化し た。一方，放射モードは，『音響パワーに対するモー ド単位の直交因子』という物理的意味を持つ。した がって, 放射クラスタは, 音響パワーに対する直交因 子としての精緻性という観点からすると, 放射モード の下位概念に相当する.すなわち, 放射モードの抑制 は, 音響パワーの抑制を確約するのに対し, 放射クラ スタの抑制は，この限りではない。これは，式(28)に おける $\mathbf{M}_{e, e}(\omega), \mathbf{M}_{o, o}(\omega)$ が一般的に非対角マトリク スであることから理解できる.放射クラスタの直交性 は, あくまでクラスタの単位で見出せるのであって, それ以上のものでも, それ以下のものでもない.

3. 2 放射クラスタ制御本節では, 各放射クラ スタを独立に計測する方法について論じ, 次いで, 各 放射クラスタを独立に励起する方法について論ずる. 簡単のため, SISO(single input single output)の観点か ら議論を始めるが, 最終的には, MIMO(multiple input multiple output) として制御系を構築してゆく. 
まず, 導入するセンサの数は, 放射クラスタの数に 合わせて2 個に設定する. また, 各々のセンサを構造 物の対称性に合わせるかたちで対称的に配置する.セ ンサ対の設置座標を $\mathbf{r}_{1, i}, \mathbf{r}_{2, i}$ としたとき(図1参照)，次 式が成り立つ。

$\psi_{e}\left(\mathbf{r}_{1, i}\right)=\psi_{e}\left(\mathbf{r}_{2, i}\right)$

$\psi_{o}\left(r_{1, i}\right)=-\psi_{o}\left(r_{2, i}\right)$

計測点の複素速度 $v\left(\mathrm{r}_{1, i}, \omega\right), v\left(\mathrm{r}_{2, i}, \omega\right)$ は, 次のベクト ル形式で整理できる.

$\overline{\mathbf{v}}\left(\mathbf{r}_{1, i}, \mathbf{r}_{2, i}, \omega\right)=\left[\begin{array}{l}v\left(\mathbf{r}_{1, i}, \omega\right) \\ v\left(\mathbf{r}_{2, i}, \omega\right)\end{array}\right]$

$=\left[\begin{array}{ll}\Psi_{e}{ }^{T}\left(\mathbf{r}_{1, i}\right) & \Psi_{o}{ }^{T}\left(\mathbf{r}_{1, i}\right) \\ \Psi_{e}{ }^{T}\left(\mathbf{r}_{2, i}\right) & \Psi_{o}{ }^{T}\left(\mathbf{r}_{2, i}\right)\end{array}\right]\left[\begin{array}{l}\mathbf{a}_{e}(\omega) \\ \mathbf{a}_{o}(\omega)\end{array}\right] \in \mathbb{C}^{2 \times 1}$

ここで, 次式の演算処理を考える.

$\tilde{\mathbf{v}}\left(\mathbf{r}_{1, i}, \mathbf{r}_{2, i}, \omega\right)=\mathbf{T} \mathbf{v}\left(\mathbf{r}_{1, i}, \mathbf{r}_{2, i}, \omega\right) \in \mathbb{C}^{2 \times 1}$

ただし，変換マトリクス $\mathbf{T} \in \mathbb{R}^{2 \times 2}$ を次式に定義する.

$\mathbf{T}=\left[\begin{array}{ll}\mathbf{t}_{e} & \mathbf{t}_{o}\end{array}\right]$

なお，

$\mathbf{t}_{\mathrm{e}}=\left[\begin{array}{ll}1 & 1\end{array}\right]^{T}$

$\mathbf{t}_{o}=\left[\begin{array}{ll}1 & -1\end{array}\right]^{T}$

$\mathbf{t}_{e} \in \mathbb{R}^{2 \times 1}$ は, 対称な計測点における偶関数の同振幅 $/$ 同位相性を考慮したものであり， $\mathbf{t}_{o} \in \mathbb{R}^{2 \times 1}$ は，対称な 計測点に扔ける奇関数の同振幅/逆位相性を考慮した ものである.このとき，式(29),(30)を式(31)に代入す ることで，次式を得られる。

$\tilde{\mathbf{v}}\left(\mathbf{r}_{1, i}, \omega\right)=\left[\begin{array}{c}\tilde{v}_{e}\left(\mathbf{r}_{1, i}, \omega\right) \\ \tilde{v}_{o}\left(\mathbf{r}_{1, i}, \omega\right)\end{array}\right]$

$=2\left[\begin{array}{cc}\boldsymbol{\psi}_{e}^{T}\left(\mathbf{r}_{\mathrm{1}, i}\right) & \mathbf{0} \\ \mathbf{0} & \boldsymbol{\psi}_{o}^{T}\left(\mathbf{r}_{1, i}\right)\end{array}\right]\left[\begin{array}{l}\mathbf{a}_{e}(\omega) \\ \mathbf{a}_{o}(\omega)\end{array}\right]=2\left[\begin{array}{l}\boldsymbol{\psi}_{e}^{T}\left(\mathbf{r}_{1, i}\right) \mathbf{a}_{e}(\omega) \\ \boldsymbol{\psi}_{o}^{T}\left(\mathbf{r}_{1, i}\right) \mathbf{a}_{o}(\omega)\end{array}\right]$

このとき, 取得された情報 $\tilde{v}_{A}\left(\mathbf{r}_{1, i}, \omega\right), \tilde{v}_{B}\left(\mathbf{r}_{1, i}, \omega\right)$ は, 計 測点 $\mathbf{r}_{1, i}$ における放射クラスタの複素速度である．以 上のとおり，少数のセンサを用意し，そのセンサの計 測信号に単純な加減算処理を施すだけで, 各放射クラ スタを独立に計測できる.この計測法は, 構造モード 関数の対称性を利用しているものの, 構造モード関数 そのものを必要としないことに留意されたい．

続いて, 各放射クラスタを独立に励起する方法につ
いて述べる. 導入するアクチュエータの数は, 放射ク ラスタの数に合わせて 2 個に設定する. また, 各々の アクチュエータを構造物の対称性に合わせるかたちで 対称位置に設置する.アクチュエータ対の設置座標を $\mathbf{r}_{1, j}, \mathbf{r}_{2, j}$ としたとき(図1参照)，次式が成り立つ.

$\psi_{e}\left(\mathbf{r}_{1, j}\right)=\psi_{e}\left(\mathbf{r}_{2, j}\right)$

$\psi_{o}\left(\mathbf{r}_{1, j}\right)=-\psi_{o}\left(\mathbf{r}_{2, j}\right)$

ここで, $L$ 個の複素外乱力 $f_{d}\left(\mathbf{r}_{i}\right)(l=1,2, \cdots, L)$, 式 (35)で作用点を定義される一対の複素制御力 $f_{1}, f_{2}$ に より励起される構造モード振幅は, 次式で得られる.

$\mathbf{a}(\omega)=\mathbf{Y}(\omega)\left\{\sum_{l=1}^{L} \psi\left(\mathbf{r}_{l}\right) f_{d}\left(\mathbf{r}_{l}\right)+\left[\psi\left(\mathbf{r}_{1, j}\right) \quad \psi\left(\mathbf{r}_{2, j}\right)\right]\left[\begin{array}{l}f_{1} \\ f_{2}\end{array}\right]\right\}$

ただし, 構造共振マトリクス $\mathbf{Y}(\omega) \in \mathbb{C}^{N \times N}$ は, 対角マ トリクスであり, 次式の対角要素 $Y_{n n}(\omega)$ を持つ.

$Y_{n n}(\omega)=\frac{j \omega}{\left(\omega_{n}^{2}-\omega^{2}+j \eta_{n} \omega_{n} \omega\right)}$

なお, $\omega_{n}$ を $n$ 次構造モードの固有角振動数, $\eta_{n}$ を $n$ 次 構造モードの減衰比とする.さらに, 式(36)は, 次式 のようにクラスタ化できる。

$$
\begin{aligned}
& \mathbf{a}(\omega)=\left[\begin{array}{l}
\mathbf{a}_{e}(\omega) \\
\mathbf{a}_{o}(\omega)
\end{array}\right]=\left[\begin{array}{cc}
\mathbf{Y}_{e}(\omega) & \mathbf{0} \\
\mathbf{0} & \mathbf{Y}_{o}(\omega)
\end{array}\right] \\
& \left\{\sum_{l=1}^{L}\left[\begin{array}{l}
\boldsymbol{\Psi}_{e}\left(\mathbf{r}_{l}\right) f_{d}\left(\mathbf{r}_{l}\right) \\
\boldsymbol{\Psi}_{o}\left(\mathbf{r}_{l}\right) f_{d}\left(\mathbf{r}_{l}\right)
\end{array}\right]+\left[\begin{array}{ll}
\Psi_{e}\left(\mathbf{r}_{1, j}\right) & \Psi_{e}\left(\mathbf{r}_{2, j}\right) \\
\boldsymbol{\Psi}_{o}\left(\mathbf{r}_{1, j}\right) & \boldsymbol{\Psi}_{o}\left(\mathbf{r}_{2, j}\right)
\end{array}\right]\left[\begin{array}{l}
f_{1} \\
f_{2}
\end{array}\right]\right\}
\end{aligned}
$$

ここで, 次式の演算処理を考える.

$\tilde{\mathbf{f}}=\left[\begin{array}{ll}\tilde{f}_{e} & \tilde{f}_{o}\end{array}\right]^{T}=\mathbf{T} \overline{\mathbf{f}} \in \mathbb{C}^{2 \times 1}$

ただし，

$\overline{\mathbf{f}}=\left[\begin{array}{ll}f_{1} & f_{2}\end{array}\right]^{T} \in \mathbb{C}^{2 \times 1}$

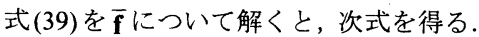

$\overline{\mathbf{f}}=\mathbf{T}^{-1} \tilde{\mathbf{f}}=\frac{1}{2} \mathbf{T}^{T} \tilde{\mathbf{f}}$

式(29),(41)を式(38)に代入し，次式を得る。

$$
\begin{aligned}
& \mathbf{a}(\omega)=\left[\begin{array}{l}
\mathbf{a}_{e}(\omega) \\
\mathbf{a}_{o}(\omega)
\end{array}\right]=\left[\begin{array}{cc}
\mathbf{Y}_{e}(\omega) & \mathbf{0} \\
\mathbf{0} & \mathbf{Y}_{o}(\omega)
\end{array}\right] \\
& \left\{\sum_{l=1}^{L}\left[\begin{array}{l}
\boldsymbol{\Psi}_{e}\left(\mathbf{r}_{l}\right) f_{d}\left(\mathbf{r}_{l}\right) \\
\boldsymbol{\psi}_{o}\left(\mathbf{r}_{l}\right) f_{d}\left(\mathbf{r}_{i}\right)
\end{array}\right]+\left[\begin{array}{cc}
\Psi_{e}\left(\mathbf{r}_{1, j}\right) & \mathbf{0} \\
\mathbf{0} & \boldsymbol{\Psi}_{o}\left(\mathbf{r}_{1, j}\right)
\end{array}\right]\left[\begin{array}{c}
\tilde{f}_{e} \\
\tilde{f}_{o}
\end{array}\right]\right\}
\end{aligned}
$$




$$
=\left[\begin{array}{l}
\mathbf{Y}_{e}(\omega)\left\{\sum_{l=1}^{L} \Psi_{e}\left(\mathbf{r}_{l}\right) f_{d}\left(\mathbf{r}_{l}\right)+\Psi_{e}\left(\mathbf{r}_{1, j}\right) \tilde{f}_{e}\right\} \\
\mathbf{Y}_{o}(\omega)\left\{\sum_{l=1}^{L} \Psi_{o}\left(\mathbf{r}_{l}\right) f_{d}\left(\mathbf{r}_{l}\right)+\Psi_{o}\left(\mathbf{r}_{1, j}\right) \tilde{f}_{o}\right\}
\end{array}\right]
$$

このとき，制御力 $\tilde{f}_{e}, \tilde{f}_{o}$ は，各放射クラスタを独立に 励起できる. 以上のように, 少数のアクチュエータを 用意し、そのアクチュエータの駆動信号に単純な加減 算処理を施すだけで，各放射クラスタを独立に励起で きる.この励起法は, 構造モード関数の対称性を利用 しているものの,構造モード関数そのものを必要とし ないことに留意されたい。

そして, 式(34),(42)を統合することで, 次式の放射 クラスタ制御系を構築できる。

$\left[\begin{array}{l}\tilde{v}_{e}\left(\omega, \mathbf{r}_{1, i}\right) \\ \tilde{v}_{o}\left(\omega, \mathbf{r}_{1, i}\right)\end{array}\right]$
$=2\left[\begin{array}{l}\boldsymbol{\psi}_{e}{ }^{T}\left(\mathbf{r}_{1, i}\right) \mathbf{Y}_{e}(\omega)\left\{\sum_{l=1}^{L} \Psi_{e}\left(\mathbf{r}_{l}\right) f_{d}\left(\mathbf{r}_{l}\right)+\Psi_{e}\left(\mathbf{r}_{1, j}\right) \tilde{f}_{e}\right\} \\ \Psi_{o}{ }^{T}\left(\mathbf{r}_{1, i}\right) \mathbf{Y}_{o}(\omega)\left\{\sum_{l=1}^{L} \Psi_{o}\left(\mathbf{r}_{l}\right) f_{d}\left(\mathbf{r}_{l}\right)+\Psi_{o}\left(\mathbf{r}_{1, j}\right) \tilde{f}_{o}\right\}\end{array}\right]$

さて, 以上の理論展開は, 対称に設置された 1 組の センサ対/アクチュエータ対から成る放射クラスタ制 御系に関するものであった.ここで, $i=1,2, \cdots, I$ 組の センサ対, $j=1,2, \cdots, J$ 組のアクチュエータ対を考え るとき，式(43)を次式に拡張できる.

$\left[\begin{array}{l}\tilde{\mathbf{v}}_{e}(\omega) \\ \tilde{\mathbf{v}}_{o}(\omega)\end{array}\right]=2\left[\begin{array}{l}\boldsymbol{\Psi}_{e, s}{ }^{T} \mathbf{Y}_{e}(\omega)\left\{\sum_{l=1}^{L} \boldsymbol{\Psi}_{e}\left(\mathbf{r}_{l}\right) f_{d}\left(\mathbf{r}_{l}\right)+\Psi_{e, a} \tilde{\mathbf{f}}_{e}\right\} \\ \Psi_{o, s}{ }^{T} \mathbf{Y}_{o}(\omega)\left\{\sum_{l=1}^{L} \boldsymbol{\Psi}_{e}\left(\mathbf{r}_{l}\right) f_{d}\left(\mathbf{r}_{l}\right)+\Psi_{o . a} \tilde{\mathbf{f}}_{o}\right\}\end{array}\right]$

ただし，

$\left[\begin{array}{c}\tilde{\mathbf{v}}_{e}(\omega) \\ \tilde{\mathbf{v}}_{o}(\omega)\end{array}\right]=\left[\begin{array}{ccccc}\tilde{v}_{e}\left(\mathbf{r}_{1,1}, \omega\right) & \cdots & \tilde{v}_{e}\left(\mathbf{r}_{1, i}, \omega\right) & \cdots & \tilde{v}_{e}\left(\mathbf{r}_{1, l}, \omega\right) \\ \tilde{v}_{o}\left(\mathbf{r}_{1,1}, \omega\right) & \cdots & \tilde{v}_{o}\left(\mathbf{r}_{1, i}, \omega\right) & \cdots & \tilde{v}_{o}\left(\mathbf{r}_{1, l}, \omega\right)\end{array}\right]$

$\left[\begin{array}{l}\Psi_{e, s} \\ \Psi_{o, s}\end{array}\right]=\left[\begin{array}{lllll}\boldsymbol{\Psi}_{e}\left(\mathbf{r}_{1,1}\right) & \cdots & \boldsymbol{\Psi}_{e}\left(\mathbf{r}_{1, i}\right) & \cdots & \boldsymbol{\Psi}_{e}\left(\mathbf{r}_{1, I}\right) \\ \boldsymbol{\Psi}_{o}\left(\mathbf{r}_{1,1}\right) & \cdots & \boldsymbol{\Psi}_{o}\left(\mathbf{r}_{1, i}\right) & \cdots & \boldsymbol{\Psi}_{o}\left(\mathbf{r}_{1, I}\right)\end{array}\right]$

$\left[\begin{array}{l}\Psi_{e, a} \\ \Psi_{o, a}\end{array}\right]=\left[\begin{array}{lllll}\Psi_{e}\left(\mathbf{r}_{1,1}\right) & \cdots & \Psi_{e}\left(\mathbf{r}_{1, j}\right) & \cdots & \Psi_{e}\left(\mathbf{r}_{1, J}\right) \\ \Psi_{o}\left(\mathbf{r}_{1,1}\right) & \cdots & \Psi_{o}\left(\mathbf{r}_{1, j}\right) & \cdots & \Psi_{o}\left(\mathbf{r}_{1, J}\right)\end{array}\right]$

$\left[\begin{array}{c}\tilde{\mathbf{f}}_{e} \\ \tilde{\mathbf{f}}_{o}\end{array}\right]=\left[\begin{array}{lllll|lllll}\tilde{f}_{e, 1} & \cdots & \tilde{f}_{e, j} & \cdots & \tilde{f}_{e, J} & \tilde{f}_{o, 1} & \cdots & \tilde{f}_{o, j} & \cdots & \tilde{f}_{o, J}\end{array}\right]^{T}$

$\left[\begin{array}{l}\tilde{f}_{e, j} \\ \tilde{f}_{o, j}\end{array}\right]=\mathbf{T}\left[\begin{array}{l}f_{1, j} \\ f_{2, j}\end{array}\right]=\left[\begin{array}{cc}1 & 1 \\ 1 & -1\end{array}\right]\left[\begin{array}{l}f_{1, j} \\ f_{2, j}\end{array}\right] \quad(j=1,2, \cdots J)$
なお， $\mathbf{r}_{1, i}, \mathbf{r}_{2, i}$ を $i$ 組目のセンサ対設置座標, $\mathbf{r}_{1, j}, \mathbf{r}_{2, j}$ を $j$ 組目のアクチュエータ対設置座標, $f_{1, j}, f_{2, j}$ を座標 $\mathbf{r}_{1, j}, \mathbf{r}_{2, j}$ に設置された一対の複素制御力とする.

最後に, 放射クラスタ $\tilde{\mathbf{v}}_{e}(\omega), \tilde{\mathbf{v}}_{o}(\omega)$ の自乗值の最 小化を考える.ここで, 式(44)加次式を展開し, こ れを評価関数と置く。

$$
\begin{aligned}
& {\left[\begin{array}{l}
\sum_{i=1}^{I}\left|\tilde{v}_{e}\left(\mathbf{r}_{1, i}, \omega\right)\right|^{2} \\
\sum_{i=1}^{I}\left|\tilde{v}_{o}\left(\mathbf{r}_{1, i}, \omega\right)\right|^{2}
\end{array}\right]=\left[\begin{array}{l}
\tilde{\mathbf{v}}_{e}{ }^{H}(\omega) \tilde{\mathbf{v}}_{e}(\omega) \\
\tilde{\mathbf{v}}_{o}{ }^{H}(\omega) \tilde{\mathbf{v}}_{o}(\omega)
\end{array}\right]} \\
& =\left[\begin{array}{c}
\tilde{\mathbf{f}}_{e}{ }^{H} \mathbf{A}_{e} \tilde{\mathbf{f}}_{e}+\tilde{\mathbf{f}}_{e}{ }^{H} \mathbf{b}_{e}+\mathbf{b}_{e}{ }^{H} \tilde{\mathbf{f}}_{e}+c_{e} \\
\tilde{\mathbf{f}}_{o}{ }^{H} \mathbf{A}_{o} \tilde{\mathbf{f}}_{o}+\tilde{\mathbf{f}}_{o}{ }^{H} \mathbf{b}_{o}+\mathbf{b}_{o}{ }^{H} \tilde{\mathbf{f}}_{o}+c_{o}
\end{array}\right]
\end{aligned}
$$

ただし，

$$
\begin{aligned}
& {\left[\begin{array}{l}
\mathbf{A}_{e}(\omega) \\
\mathbf{A}_{o}(\omega)
\end{array}\right]=4\left[\begin{array}{c}
\Psi_{e, a}{ }^{H}\left\{\mathbf{Y}_{e}(\omega)\right\}^{H} \Psi_{e, s}{ }^{~} \Psi_{e, s}{ }^{T} \mathbf{Y}_{e}(\omega) \Psi_{e, a} \\
\Psi_{o, a}{ }^{H}\left\{\mathbf{Y}_{o}(\omega)\right\}^{H} \Psi_{o, s}{ }^{~} \Psi_{o, s}{ }^{T} \mathbf{Y}_{o}(\omega) \Psi_{o, a}
\end{array}\right](51)} \\
& {\left[\begin{array}{l}
\mathbf{b}_{e}(\omega) \\
\mathbf{b}_{o}(\omega)
\end{array}\right]=4\left[\begin{array}{l}
\Psi_{e, a}{ }^{H}\left\{\mathbf{Y}_{e}(\omega)\right\}^{H} \Psi_{e, s}{ }^{~} \Psi_{e, s}{ }^{T} \mathbf{Y}_{e}(\omega) \sum_{l=1}^{L} \Psi_{e}\left(\mathbf{r}_{l}\right) f_{d}\left(\mathbf{r}_{l}\right) \\
\Psi_{o, a}{ }^{H}\left\{\mathbf{Y}_{o}(\omega)\right\}^{H} \Psi_{o, s}{ }^{~} \Psi_{o, s}{ }^{T} \mathbf{Y}_{o}(\omega) \sum_{l=1}^{L} \Psi_{e}\left(\mathbf{r}_{l}\right) f_{d}\left(\mathbf{r}_{l}\right)
\end{array}\right]}
\end{aligned}
$$

$\left[\begin{array}{l}c_{e}(\omega) \\ c_{o}(\omega)\end{array}\right]=4\left[\begin{array}{l}\sum_{l=1}^{L} \Psi_{e}{ }^{H}\left(\mathbf{r}_{l}\right) f_{d}^{*}\left(\mathbf{r}_{l}\right)\left\{\mathbf{Y}_{e}(\omega)\right\}^{H} \Psi_{e, s}{ }^{*} \\ \sum_{l=1}^{L} \Psi_{o}{ }^{H}\left(\mathbf{r}_{l}\right) f_{d}^{*}\left(\mathbf{r}_{l}\right)\left\{\mathbf{Y}_{o}(\omega)\right\}^{H} \Psi_{o, s}{ }^{*}\end{array}\right.$

$$
\left.\begin{array}{l}
\Psi_{e, s}{ }^{T} \mathbf{Y}_{e}(\omega) \sum_{l=1}^{L} \boldsymbol{\psi}_{e}\left(\mathbf{r}_{l}\right) f_{d}\left(\mathbf{r}_{l}\right) \\
\Psi_{o, s}{ }^{T} \mathbf{Y}_{o}(\omega) \sum_{l=1}^{L} \boldsymbol{\psi}_{e}\left(\mathbf{r}_{l}\right) f_{d}\left(\mathbf{r}_{l}\right)
\end{array}\right]
$$

式(50)がエルミート二次形式[22]であることから, 当 該評価関数を最小とする制御則は, 次式で得られる.

$$
\left[\begin{array}{c}
\tilde{\mathbf{f}}_{e, o p t}(\omega) \\
\tilde{\mathbf{f}}_{o, o p t}(\omega)
\end{array}\right]=\left[\begin{array}{l}
-\mathbf{A}_{e}^{-1}(\omega) \mathbf{b}_{e}(\omega) \\
-\mathbf{A}_{o}^{-1}(\omega) \mathbf{b}_{o}(\omega)
\end{array}\right]^{T}
$$

以上のとおり, 放射クラスタ制御系は, 構造物の対 称性に合わせてセンサ対／アクチュエータ対を配置 し,これらの計測信号／駆動信号に加减算処理を施す だけで，極めて容易に実装できる．また，当該制御系 は, 音響場に対する直交因子の計測／制御に基礎を置 くため，合理的な放射音制御を期待できる.ただし， 放射クラスタの直交性は,クラスタ単位で担保される のであり,モード単位で担保されるのではない.した がって, 放射クラスタ制御は, 放射音制御系としての 合理性という観点からは, 放射モード制御の下位概念 に相当する.すなわち, 放射クラスタ制御は, LACの 
実用性とHACの合理性を折衷した MAC(middle authority control) として位置付けられる.

\section{4. 結言}

対称構造物を対象として,合理的かつ実用的な放射 音制御系を提案した. 本論文の成果をまとめると, 下 記の通り.

[1] 対称構造物を考えるとき, 構造モード関数は, 偶 関数か奇関数に帰属する. そこで, 偶関数に帰属する 構造モードから成るクラスタ, 奇関数に帰属する構造 モードから成るクラスタを定義した。

[2] 上記のクラスタが音響場における直交因子である ことを数学的に証明した。また, 当該クラスタを放射 クラスタ (radiation cluster) と命名した.

[3] 放射クラスタの直交性は, クラスタ単位で成立す る. すなわち, 放射クラスタは, モード単位の直交因 子として知られる放射モードの下位概念に相当する. [4] 放射クラスタの計測／制御に関する理論を構築し, 放射クラスタ制御を提案した. 当該制御系は, 構造物 の対称性に合わせるかたちでセンサ対／アクチュエー 夕対を設置し,それらの計測信号／駆動信号に単純な 加減算処理を施すだけで, 容易に実装できる.

[5] 放射クラスタ制御は, LAC(low authority control:構 造モード制御)の実用性と HAC(high authority control: 放射モード制御)の合理性を折哀したMAC(middle authority control) として位置付けられる.

\section{文献}

[1] P. A. Nelson, A. R. D. Curtis, S. J. Elliott, and A. J. Bullmore, "The minimum power output of free field point sources and the active controlof sound $\cdot J$. Sound and Vib. 116, (1987), pp. 397-414.

[2] K. A. Cunefare and G. H. Koopmann, "A boundary element approach to optimization of active noise control sources on three-dimensional structures", Trans. ASME. J. Vib. Acoust. 113, (1991), pp. 387-394.

[3] S. D. Snyder and Nobuo Tanaka, "On feedforward active control of sound and vibration using vibration error signals", J. Acoust. Soc. Am. 94, (1993), pp. 2181-2193.

[4] S. D. Snyder and C. H. Hansen, "Mechanisms of active noise control by vibration sources", J. Sound and Vib. 143, (1991), pp. 519-525.

[5] J. Pan, S. D. Snyder, and C. H. Hansen, "Active control of far-field sound radiated by a rectangular panel: A general analysis", J. Acoust. Soc. Am. 91, (1992), pp. 2056-2066. [6] G. V. Borgiotti, "The power radiated by a vibrating body in an acoustic fluid and its determination from boundary measurements", J. Acoust. Soc. Am. 88, (1990), pp. 1884-1893.

[7] K. A. Cunefare, "The minimum multimodal radiation efficiency of baffled finite beams", J. Acoust. Soc. Am. 90, (1991), pp. 2521-2529.

[8] G. V. Borgiotti and K. E. Jones, "Frequency independence property of radiation spatial filters", J. Acoust. Soc. Am. 96, (1994), pp. 3516-3524.

[9] M. N. Currey and K. A. Cunefare, "The radiation modes of baffled finite plates", J. Acoust. Soc. Am. 98, (1995), pp. 1570-1580.

[10] K. A. Cunefare and M. N. Currey, "On the exterior acoustic radiation modes of structures", J. Acoust. Soc. Am. 96, (1994), pp. 2302-2312.

[11] K. A. Cunefare and M. N. Currey, "The radiation efficiency grouping of free-space acoustic radiation modes", J. Acoust. Soc. Am. 109, (2001), pp. 203-215.

[12] W. T. Baumann, W. R. Saunders, and H. H. Robertshaw, "Active suppression of acoustic radiation from impulsively excited structures", J. Acoust. Soc. Am. 90, (1991), pp. 3202-3208.

[13] S. J. Elliott and M. E. Johnson, "Radiation modes and the active control of sound power", J. Acoust. Soc. Am. 94, (1993), pp. 2194-2204.

[14] G. P. Gibbs, R. L. Clark, D. E. Cox, and J. S. Vipperman, "Radiation modal expansion: Application to active structural acoustic control", J. Acoust. Soc. Am. 107, 2000, pp. 332-339.

[15] A. P. Berkhoff, "Sensor scheme design for active structural acoustic control", J. Acoust. Soc. Am. 108, (2000), pp. 1037-1045.

[16] A. P. Berkhoff, "Broadband radiation modes: Estimation and active control", J. Acoust. Soc. Am. 111, (2002), pp. 1295-1305.

[17] T. Chanpheng, H. Yamada, T. Miyata, and H. Katsuchi, "Application of radiation modes to the problem of lowfrequency noise from a highway bridge", Applied Acoustics 65, (2004), pp. 109-123.

[18] N. Tanaka and Y. Kikushima, "Active control of distributed-parameter structure: Proposition of cluster control", Trans. JSME. Ser. C. 64, (1998), pp. 780-787.

[19] N. Tanaka and S. D. Snyder, "Cluster control of a distributed-parameter planar structure: Middle authority control", J. Acoust. Soc. Am. 112, (2002), pp. 2798-2807. [20] T. Kaizuka and N. Tanaka, "Radiation cluster control in symmetric enclosures: Theoretical development of radiation cluster control system", Trans. JSME. Ser. C., under review.

[21] K. Naghshineh and G. H. Koopmann, "A design method for achieving weak radiator structures using active vibration control", J. Acoust. Soc. Am. 92, (1992), pp. 856-870. [22] S. D. Snyder and C. H. Hansen, "The design of systems to control actively periodic sound transmission into enclosed spaces, part 1: Analytical models", J. Sound and Vib. 170, (1994), pp. 433-449. 